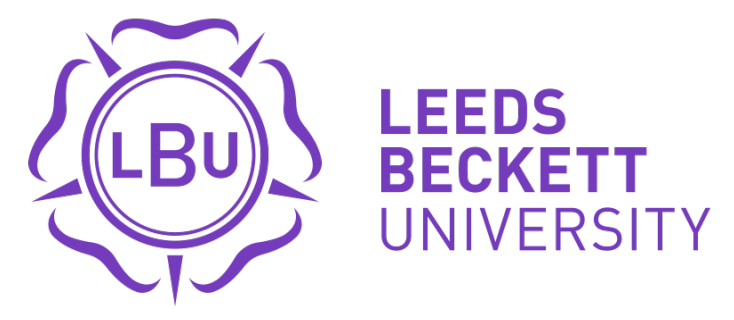

Citation:

Hills, J and Lees, J and Freshwater, D and Cahill, J (2016) Psychosoma in crisis: an autoethnographic study of medically unexplained symptoms and their diverse contexts. British Journal of Guidance and Counselling, 46. pp. 135-147. DOI: https://doi.org/10.1080/03069885.2016.1172201

Link to Leeds Beckett Repository record:

https://eprints.leedsbeckett.ac.uk/id/eprint/6100/

Document Version:

Article (Accepted Version)

Creative Commons: Attribution-Noncommercial-No Derivative Works 4.0

This is an Accepted Manuscript of an article published by Taylor \& Francis in British Journal of Guidance \& Counselling on 13th April 2016, available online: http://www.tandfonline.com/10.1080/03069885.2016.1172201.

The aim of the Leeds Beckett Repository is to provide open access to our research, as required by funder policies and permitted by publishers and copyright law.

The Leeds Beckett repository holds a wide range of publications, each of which has been checked for copyright and the relevant embargo period has been applied by the Research Services team.

We operate on a standard take-down policy. If you are the author or publisher of an output and you would like it removed from the repository, please contact us and we will investigate on a case-by-case basis.

Each thesis in the repository has been cleared where necessary by the author for third party copyright. If you would like a thesis to be removed from the repository or believe there is an issue with copyright, please contact us on openaccess@leedsbeckett.ac.uk and we will investigate on a case-by-case basis. 


\section{Psychosoma in Crisis: An autoethnographic study of medically unexplained symptoms}

\section{and their diverse contexts}

John Hills, Dr John Lees, Professor Dawn Freshwater \& Dr Jane Cahill

School of Healthcare, the University of Leeds

Word length: 7600

John Hills

(research conducted at

University of Leeds for MA in

Counselling and

Psychotherpy)

74 High Street, Boston Spa, Wetherby, West Yorkshire, LS23 6EA

(01937) 541723

johnhillsmusic@ hotmail.com

Prof Dawn Freshwater

School of Healthcare, Baines

Wing, The University of

Leeds, LS2 9JT

01133437963

d.freshwater@leeds.ac.uk
Dr John Lees

(corresponding author)

School of Healthcare, Baines

Wing, The University of

Leeds, LS2 9JT

01133433911

j.lees@leeds.ac.uk
Dr Jane Cahill

School of Healthcare, Baines

Wing, The University of Leeds,

LS2 9JT

01133431468

i.l.cahill@leeds.ac.uk 


\begin{abstract}
In this study we examine autoethnographic data from three critical incidents as experienced by the first author (FA) demonstrating the importance of context in understanding medically unexplained symptoms, their incidence and underlying patterns. We make the case for ethnographies as a crucial research strand in discerning the finer aspects of the patient or client experience; aspects that might be missed where people are directed along protocolised pathways of care. The article describes care as fragmented and depersonalising, leading to disembodied exchanges, as reflected in other autoethnographic studies, particularly those that highlight the complex relationship and controversies surrounding diagnostic uncertainty. We observe that psychological therapists, given the quality of the therapeutic relationship and sustained attention to the person's experience, are well placed to assist in the necessary processes of re-contextualisation and re-embodiment.
\end{abstract}

Key words: psychosomatic pain, medically unexplained symptoms, trauma, patient narratives, depersonalisation, autoethnography

\title{
Introduction
}

Medically unexplained symptoms account for up to one in five of all GP consultations and 30\% of these are subsequently found to have an associated psychiatric disorder - usually depression or anxiety (RCGP, 2014). It is generally understood that medically unexplained and somatic 
symptoms can be triggered or exacerbated by emotional distress, which the person can experience directly or indirectly. A 2010 study found up to $10 \%$ of all NHS spending was incurred by somatising patients, and the total cost including sickness absences to be over $£ 14$ billion per annum (Bermingham et al, 2010). Common examples of physical symptoms that may arise or are exacerbated during times of emotional distress include eczema, alopecia, fibromyalgia, or irritable bowel syndrome.

Contemporary literature suggests a stigma associated with pain and other symptoms where there is a diagnostic uncertainty (e.g. Wilbers, 2015; Anderson et al, 2012; Gask et al, 2011). This can lead to suspicion and breakdowns in the relationships between the sufferer and health practitioners, their carers, family members, and other interested parties such as employers. The sufferer may feel that nobody understands them leading to, and perpetuating existing, feelings of alienation.

Controversy and confusion surround terms such as 'psychosomatic' and 'psychogenic' - with existing evidence suggesting that these terms still imply that symptoms are 'all in the mind' and thus that 'there's nothing wrong with you' (Ricciardi, 2014; Leone, 2011). Many people dread such a diagnosis because the implication is that their symptoms will no longer be taken seriously (Hinton et al, 2016; Mobini, 2015). Some strongly resist and fiercely reject the idea of a psychological element to their symptoms/experience and may even believe their symptoms indicate that something is seriously wrong but is being missed.

The current study is a continuation of previous research into the topic by the First Author (FA), a trained psychological therapist, having himself suffered from chronic pain for sixteen years. This culminated, in 2014, in an autoethnographic study into chronic pain, and what appeared to be its psychosomatic qualities. As in all ethnographic study, particular attention is drawn to the contexts in which events acquired meaning, and it was discovered that these contexts had 
significant therapeutic value. This article will explore three critical incidents typical of the data derived from the study and we will use these to highlight the importance of context. In doing so we make the wider case for ethnography as a crucial research strand for advancements in the ways psychological therapists work with somatisation and medically unexplained symptoms (MUS).

\section{MUS and the Counselling and Psychotherapy Profession}

The substantive literature on MUS comes from medical discourses. Yet there is a continued reluctance in the counselling and psychotherapy (therapy) profession to engage with this literature, with strong antagonisms sometimes expressed by counselling and psychotherapy (therapy) practitioners towards the medical model (Lees, 2011). This, arguably, began with the work of Carl Rogers in the early 1950s when he used the term 'clients' rather than 'patients'. The challenges to the medical model have increased in recent years in response to the increasing influence of evidence based practice and managed care on the profession with its emphasis on medical model principles (Lees, 2016). This development has, for several years, been rebutted by some therapists: therapy is 'not a branch of medicine nor an activity ancillary to medicine. Most forms of therapy do not focus exclusively on the relief of symptoms, but emphasise creating and exploring a relationship' (Alliance, 2009). Attitudes, leading to a disinterest in medically-orientated literature, are problematic since this literature contains many valuable insights. In contrast to such antagonisms, the article unashamedly draws on medically-orientated literature and aims to break down the conceptual barriers separating these disciplines. Moreover, we believe it is essential to maintain a congruence between the approach taken in the current study, that is holistic and integrative, and the problematising of the psyche-soma split. 
One primary criticism leveled against medical thinking is that it fails to take into account social, political and economic factors; that is to say, it is reductive. Yet there is a substantial body of literature which includes client stories which stands between medically-orientated and psychotherapeutic literature and this 'intermediate' literature includes contextual factors (Fisher and Lees, 2015). Indeed this study will cite several examples of this literature. It will also adopt ethnographic methods which are explicitly concerned with examining conceptual factors.

\section{Ethnography and patient narratives}

There is a clear case to be made for ethnography and patient narratives in the field of healthcare research. Andersen and Risør (2014) observed that even where qualitative research is undertaken, for example in research into why a patient may delay seeking healthcare, the themes that are extracted are often 'one-way' and have the quality of 'thin description' (in contrast to 'thick description' in Geertz, 1973) that limit the capacity of the research to provide genuine and useful insight into the lived experience of the patient. The authors observed that where themes are identified, such as the patient not wanting to bother their GP or to appear as a hypochondriac, or where a woman delays healthcare seeking because she 'did not put herself first' there is little or no investigation into the social and historical contexts of why a patient might have these attitudes.

A substantial body of auto-ethnographic literature demonstrates its value as a methodological approach (good examples include Neville-Jan 2003 and Ettore, 2005) in providing insights into the lived experience of symptoms. Wilbers, whose (2015) autoethnography explored the impacts and meanings of her mother's chronic pain and treatment, made the case for patient narratives so that practitioners may more fully appreciate and even anticipate the patient 
experience, and argued that this may have tangible implications for, say, whether or not to prescribe medication. Following spinal cord injury that resulted in permanent paralysis Clifton (2014) wrote that 'narrative storying' can help the patient work through the grief of losing the use of their limbs and indeed the life that they had before the injury, but believed there was not enough literature available about the processes of adapting to life-changing injuries and illnesses that would have helped him as a patient going through it. Barry (2006) argued that a problem with Randomised Controlled Trial methodologies was that they measured the easily measurable and typically excluded subtle, but complex, inputs and outputs. Furthermore she argued that these same methodologies typically excluded or only gave passing consideration to the contexts in which pathologies appeared, citing evidence from psychoneuroimmunology that a person's prognoses could be heavily determined by their beliefs about health and disease. Barry noted that 'the use of anthropological forms or evidence may be more helpful in providing a measure of how therapies are working on the real patient in the real world, not on the statistically average patient.'(ibid p2655).

In this article our intention is to add to the literature on the patient's lived experience by providing a narrative, 'thick description' (Geertz, 1973) of an experience of medically unexplained symptoms and the biopsychosocial contexts in which they are situated. As an autoethnogaphic study, the investigation is based on lived experience as the primary data source. An ethnographer records 'scratch notes' as they listen and observe so as to aid memory during later analysis (Suzuki et al 2005). During the formal period of research in 2014, an app on a phone was used to record any impressions about experience, physical or otherwise, that felt pertinent to the study of chronic pain and several times a week this raw data was explored for meaning through purposeful diarying. During and after observation, ethnographers ask questions about the meaning of behaviour and events (Gerrish and Lacey, 2010). The raw data 
is the 'tip of iceberg' - the visible $10 \%$ of the berg indicating an invisible $90 \%$ percent submerged in the depths - and the diary considered what might be indicated by the particular data that had been recorded. Very often links from present experience would be established to historical events, memories and dream material. The app took on the character of a seismograph as the FA was able to record each 'tremor' in real-time. The practice of recording experience in this way facilitated the development of an embodied awareness which enabled the psychosocial triggers and patterns underpinning the flare ups of his physical symptoms to be understood more directly - a habit cultivated during the formal research period which Roth (2012) describes as 'perceptual tuning'. We will consider later the implications for practice of the findings of this research and how as practitioners we can assist sufferers of medically unexplained symptoms to develop their own embodied awareness, make sense of their condition and manage the psychosocial impacts, for example on identity and relationships.

The following sections describe three critical incidents from the FA's autoethnographic research regarding chronic pain. Each incident is described in the form of thick description which includes the psycho-social context of the experience. It is then followed by a brief reflection to link the experience to the extant literature. In the first incident, the FA's lived experience of his pregnant wife's ultrasound scan and his symptoms unexpectedly flaring up 'sets the scene' in terms of establishing contextual reference points in the present day. The second incident is a historic event - a traumatic bereavement experience at the age of eighteen seems to have been the origin of his chronic symptoms. The final incident, an anxiety attack on a bus, captures the experience of depersonalisation - an 'out of body experience' that will help us to demonstrate the dynamics of disassociation, its links to 'conservation withdrawal' mechanisms that perform a comparable function to the fight or flight reflex. Each narrative stresses the physical elements of the experience, and indeed grounds experience in the physical 
frame of reference. Our purpose is to challenge the dualistic concept of mental distress vis-àvis physical distress that still prevails in conventional medicine (Edwards et al, 2010) and which is now infiltrating the therapy profession as a result of the influence of governmentsponsored therapy in the form of the IAPT scheme. One problem with this scheme is that complex and multi-faceted problems are presented as being treatable by psychological therapists who do not have an understanding of the broader context (see Lees, 2016). Placing somatic experience at the centre of the narrative is appropriate in a discussion of psychological phenomena today in view of the recognition, in recent years, of the somatic aspects of psychological problems. This idea has been around for a long time (Steiner, 1920) but has, more recently, been acknowledged by a considerable number of scientific researchers who have identified the relationship between trauma and the autonomic nervous system (Quilmann, 2013), the body's systems in general (allostatic load) (McEwen, 2000), the endocrine system (Meany, 2001) and the immune system (Ramo-Fernandez, et al, 2015). Whilst an autoethnographic case study is unique, the study aims to have relevance beyond a single case by resonating with the experiences of others who present with medically unexplained symptoms, and the experiences of the practitioners who try to help them. As Roth (2012) observed, the purpose of first-person research is to critically investigate phenomena in such a way as to articulate experience in terms of 'concrete universals' (ibid, p17). A central perspective of the study, which we will return to later, is considering the practical consequences that stem from a person's lived experience of having a body vis-à-vis being a body. In this account we will take the latter view and chart a personal journey, undergone by the FA of reembodiment in thought and emotion. 


\section{Data: critical incidents}

\section{Critical incident one: an unexpected surge of myofascial pain}

A June day in 2014. I am sitting in the driver's seat with my feet operating the pedals, my hands on the steering wheel, shifting the gears where necessary. The roads are busy outside the frame of the vehicle though I manage to synchronise our motion with the rest of the traffic smoothly. I'm gripping the wheel a little tighter than necessary, my shoulders a little hunched. My wife is sat in the passenger seat, her seatbelt positioned so as to avoid her 'bump' - not noticeable yet to those who don't know - and yet cushioned within a spherical layer of amniotic fluid, and anchored by life giving cords, are two tiny little embryos, less than $10 \mathrm{~cm}$ in length each. The prevailing idea that takes form in my mind is of having to drive safely, I increase our distance from the other vehicles, protecting our precious cargo from the threat of any sudden jerks or collisions. I'm 32 and yet feel quite naïve, as though I don't really know what I'm doing, as though I were assuming the responsibility of a far better man than myself, a man far more 'together' than I feel. Parking up and emerging from the car our physical mode shifts now - I lift up my chest and shoulders, and although nerves would propel me along at a much faster pace, I consciously match my wife's footsteps, because this is my role at this moment. As we enter the General Infirmary and traverse its long, utilitarian corridors, we feel anxious. It has been four weeks now since we last 'heard' from our twins - in all that period where they are not being scanned, where their heartbeats are not being measured, anything could have happened, they could be struggling in there, or worse, and we wouldn't have any idea about it. We take our seats in the waiting room with other mothers, the occasional awkward looking dad, and restless older children. I place my hands self-consciously on my thighs and as we 
exchange words I feel a little exposed, because the others in the room can hear what we are saying. The radiologist calls us in - a Malaysian nurse with a warm smile and a confident professionalism about her. The room is dark, the jelly is cold on my wife's tummy, we are all very polite and make nervous jokes. The ultrasound images come into focus on the screen above the bed as a figure appearing out of a blizzard. The nurse announces "twin one" but we have already seen him - his head, his nose, his arms, his legs, and his little heart visibly beating away. My eyes fill with tears and I look to my wife who is the same. The nurse takes many measures of our son's physiology, those crucial indexes of his health and development. Then she introduces us to "twin two" and there she appears, wriggling and kicking, testing out her muscles - our daughter, so alive and so real. We emerge from the dark room grinning and I feel a little guilty, not knowing what kind of a day the other families in the waiting room were having. As we make our way back through and out of the hospital our pace is different now the clock has been reset and everything is fine. I feel a familiar pain begin to creep across my face, starting at the base of my jaw bone - a raw feeling, a burning and a sore tightness. As we excitedly exchange reflections on what we learned today I feel the pain increasing and wonder why of all times the pain would be surging now. The tipping point must have been my experience of the scan - was it the twins' clean bill of health, the relief that I must have felt; was it perhaps the heralding of a different phase of anxiety - they're healthy so now I have the luxury of worrying about my responsibilities as father and provider, am I really big enough and strong enough for this task? 
The next critical incident articulates the original psychosocial context in which the MUS first emerged.

\section{Critical incident two: a trauma after a sudden death}

A Friday evening in June, in the year 2000. I'm eighteen years old, and I have just come through the door of our terraced house in West Yorkshire. The grownups are away - they've gone on a road trip. The house suggests silently the jobs I was meant to be doing; plants that need watering, a pile of washing by the sink. The A-level exams are still in process but I seem not to be taking these very seriously. Today I've been working in a factory, packing boxes - I couldn't pass up on the chance at some extra cash. I feel excited as the weekend is just beginning. Soon people start arriving, and the whole tone of the house changes - the volume increases, the music brings its own atmosphere, joints are being rolled and smoked, the smoke infuses throughout the living room and the kitchen. I have only recently discovered ecstasy, and I take two now - swallowing the chalky, bitter tasting pills down in one go with a swig of water, feeling slightly nauseated in the process. There is a knock on the door and I go straight for it, but I see before I get there that there is a policeman on the outside. I panic and call out 'it's the police' and quickly everyone scarpers to hide anything incriminating. I feel a wave of panic come over me - that naughty boy feeling of butterflies when you know you're in a lot of trouble. However the policeman is not interested in the drugs. How exactly he broke the news is now something of a hole in my memory but I learn that there has been a road accident. Two members of our family are dead and another is critically ill in hospital. What I do remember is feeling like I am losing my balance; staggering back into the living room, crying without restraint. Then I head back through the front door and cry some more out in the road. The policeman, even I can tell, is finding this assignment extremely difficult and doesn't quite know 
what to say or do. The next few hours are a blur - phone calls made to the hospital for news and to others who might be able to help. I remember the familiar physical sensations of the ecstasy starting to take effect - a warm tingling in my extremities and a lightness that passes throughout my body, pleasure in every inhale and exhale. And I feel guilty for having this completely inappropriate physical experience amidst this disaster scene.

The morning after the physical experience is typical of any 'come down' from an ecstasy trip as I experienced them - slight nausea; slight headache; heavy eyes; concentration that slips and slips almost like a fever; and crucially a sore jaw. The sore jaw is a typical experience amongst ecstasy users - during the high, one typically grinds their teeth and tenses their jaw muscles for hours on end. Usually the soreness dissipates over the day or so; I am the only one as far as I know whose jaw pain became chronic after a period of ecstasy use. The jaw pain is a permanent feature in my life - some days are harder than others but the intensity of the pain seems to depend very much on what is currently happening; my present environment and experience.

The common factor in these two otherwise disparate critical incidents the physical experience of pain. It is beyond reasonable doubt that the body is remembering and in a sense reliving something of that time, but what is it actually remembering? Rothschild suggests that we look beyond (or beneath) the narrative memory of that traumatic time; that is to say, we look to implicit memories (Rothschild, 2000). Implicit memories are those that are not rooted in one particular time or situation - most of us know how to hold and use a pen without needing to recall the particular times in childhood when we learned these skills. We remember the physical procedure and we do this remembering without thought. I form a mental picture of Pavlov's dogs, salivating upon the sound of the bell, as Rothschild makes the case that posttraumatic stress symptoms are examples of classic conditioning - the entirely healthy way in which we make associations between particular stimuli and concomitant events/consequences, 
typically so that we have a preconscious means of detecting and avoiding situations that are dangerous or frightening, or of being drawn to situations that may hold the promise of something good. Implicit elements of traumatic experience may be identified: these would not be unique to that situation but would be elements we will have encountered before and indeed have encountered since. That night, as with any ecstasy trip, concentration drifted. It would not hold in place; I felt groundless, not able to take hold of a situation that seemed to slip through my fingers. I remembered feeling hollow - almost literally out of not eating, but also of being a little fragile and exposed, the way you might feel if you were coming down with a cold but you were still at work or had business to do in town. The tidal wave of events seemed to sweep me up violently and without my consent leading to the experience of becoming a passenger and to the fact that an ability to surf upon or otherwise navigate these currents of life was found wanting; beyond my capability and level of skill. Continuing the seafaring metaphor, in such situations the vessel may appear steady and under control, but I am merely bailing out the water. Seen through this lens the jaw pain is not so much a symbol pointing back to that particular time and situation, but rather an index to a complicated web of associations - certain physical modes that I shift through in many diverse times and situations. It became what Freud might have called a 'boundary idea' (Freud 1954, p154) - a symbol that can enter consciousness and indeed prevail in consciousness; it is associated with the trauma but crucially along a chain of associations is one step removed - its function being to protect us from a conscious reliving of the traumatic experiences. As to the question of why it was that jaw pain became that symbol, Freud would perhaps have regarded it as quite appropriate:

If the traumatic event formed an outlet for itself in a motor manifestation, it will be this that becomes the boundary idea and the first symbol of the repressed material' (ibid p.154). 
In the traumatic situation I was powerless, there was very little I could actually do, but channeling all that excess tension to the jaw was something that I was inadvertently doing, and this pattern appears to have become locked in.

\section{Reflection: themes of alienation in the patient experience}

Writing about her mother's experiences living with chronic pain, Wilbers observed that when the physician can discern no tangible 'cause' of the pain, and where there is no objective way of quantifying the pain, that sufferers of chronic pain can feel their symptoms are not being taken seriously, they can't surely be as bad as they are making out (2015). Wilbers reflects that when there is 'diagnostic uncertainty' about the cause of the pain, there can be a stigma associated with the person and their complaints that would not be present had they been suffering with a legitimate diagnosis such as cancer. In such circumstances physicians can become suspicious about a person's motivations, suspecting secondary gains such as a person's desire for disability benefit payments or opioid base pain killers (ibid). The danger of this growing suspicion between doctor and patient is this can lead to the relationship becoming strained or even hostile and thus the collapse of any capacity for empathy that may have been possible (Elwood, 2012). When Ann Neville-Jan's doctor decided that her own pain was 'psychogenic' she felt this was tantamount to him washing his hands of the situation - if the pain was 'all in the head' then somehow it wasn't real (Neville-Jan, 2003). Subsequently she feared admitting to doctors she was taking antidepressants in case this only validated their dismissal of her physical complaints. However in her autoethnography Neville-Jan neatly dispatched with the false dichotomy between mental and physical aetiology: 'Is it psychogenic or real? The answer is it's pain.' (ibid). Neville-Jan reported feeling the pressure to 
deliberately look unwell for her consultations; she felt as though the doctor would be looking at her and thinking that she looked too good to be suffering as much as she said. The FAs experience of chronic pain is that although it is never debilitating, it is a permanent fixture of his experience, it always makes it presence known, and yet in the medical consultations he appears to be fit, well and functioning; thriving even. Under the care of a dental surgeon, he was once asked to rate his pain on a scale of 0 to 10 where 0 was no pain at all and 10 was worst pain ever. He struggled with placing his experience on a one-dimensional scale when it seemed to take on meaning, value and quantity in the context of an ecology of references and associations. He felt the pressure to talk up his pain and so gave it a ' 7 '. Months later, following a treatment of botox injections that was intended to paralyse his jaw muscles and thus afford them a rest, he was asked to give his pain another rating. His best answer at that time was a ' 5 ' that the surgeon then cited as evidence that the botox injections had made a positive difference although he sat there knowing that the injections had not made any difference and mumbled something to the effect that he must have overstated the pain in the first place. Such is the challenge of communicating an intensely subjective experience in such a fashion such as it can be ascribed an economic value.

Although the various practitioners were courteous, kind even, he has felt like a piece of flesh to be worked on, as a mechanic would work on a broken down machine. The FA has been prescribed a change of diet, jaw exercises, pain killers, anti-depressants, a mouth guard to wear in the nighttime, and the aforementioned botox injections for the pain. Independently he has tried osteopathy, has bought magnesium oils to rub into the site of the jaw tension, and has had two long term periods of counselling. However all those diverse treatments were experienced as so many fragments - they threw the kitchen sink at it and nothing helped. This left him feeling frustrated, at a loss of faith that anything now can make any difference with 
corresponding feelings of self-blame and failure, an experience reported by other sufferers of chronic pain (as in Doran, 2014). The image is of a patient who has no voice, no capacity to articulate his own illness and is only playing a passive role within his own care. Aside from a basic exchange of information between patient and practitioner, the conversation between them can typically be little more than a social convention whilst the practitioner does their work. This localism is understandable - to treat a cancer we need to kill or otherwise take out the cancerous cells; to fix a hearing impairment a hearing aid is fitted. However the physical site may be more appropriately considered as the epicentre of the pathology, and from here its effects out through the whole body. As Kierans observed in the narratives of people with chronic kidney failure: 'Headaches, nausea, pain, excesses of bodily hair, weight gain, and so on are also markers of manifold bodily sensations and imagery that become subject to constant interpretation and meaningmaking.' (2005 p348). It may even be that the physical site of the pathology may serve as the material symbol of a more complex pathology. So, in this study, as discussed, the jaw pain is also an index for mental states that include the slipping of attention, the inability to get a foothold, or the feeling of being out of one's depth. To work at the physical site of pain alone would seem a rather primitive attitude - if the smoke alarm is sounding we would not necessarily try to repair the alarm itself but search for the source of the smoke.

We hypothesise that such examples of unacknowledged pain, dismissal of the client's point of view and therapeutic pressure to conform to the practitioner's point of view are pervasive in the therapy profession as well as the medical profession. The failure to acknowledge the client's point of view is well-documented. Fonagy and Bateman (2006), speaking specifically about borderline personality disorder, ascribe the phenomenon to the therapist's failure to understand mentalisation and see the client's mind as separate from the therapist's mind. Driven by clinical theory, relational or otherwise, the therapist fails to 
appreciate the state of mind of the client. This may result in pseudo mentalising in which the client tries to please the therapist by conforming to his/her point of view as in the above examples or it may lead to anger (ibid, p.2) or just failing to return to sessions. Lees (2016b) gives an example of failing to address the physical pain of a client suffering from Parkinson's disease because of a preoccupation with relationality and how it was necessary for the therapist, once he had realized this, to comment on the distance between the client's and the therapist's point of view.

The next critical incident gives a thick description of the FA's experience of depersonalisation which seems to indicate a dysfunctional relationship between the conscious, decision making parts and other body parts more typically in the autonomic domain. Subsequent reflection indicates that dissociative symptoms serve as another psychosomatic response to the original traumatic episode.

\section{Critical incident three: depersonalisation attack on the bus whilst reading a newspaper}

A bright May afternoon in 2013. I'm standing at a bus stop in the centre of town with one or two others looking down the road waiting for our bus to appear. I've just been to a meeting and am smartly dressed, I had made a lot of notes and have a lot of ideas to digest but rather than digesting them now I am allowing my thoughts just to wander, and this is more out of tiredness than any healthy decision - too much for me to process right now. As the bus arrives I take my usual window seat and retrieve the newspaper from my bag. My physical experience is of being firmly planted in my seat, my body shifting as the bus turns, my arms are raised 
before me and the texture of the newspaper between my thumb and fingers is rough. My attention tunes in to the content of the newspaper and I read through an article as long as it holds my interest - in the Middle East Israeli jets have entered Syrian airspace to target a weapons facility, and in Germany a 93 year old former Auschwitz guard has been arrested on charges of murder. I 'forget' that I'm sat on my seat on the bus, or about the pressure the window makes against my arm and shoulder as we go around a corner, and particularly about the feel of the paper in my hands - my awareness is centered around the content of the individual articles and my reactions to them; the judgements I make. There's nothing strange about this - neurobiologist Bernard Baars referred to the spotlight of selective attention (Blackmore, 1996); that in consciousness remain only the necessary elements as illuminated by the spotlight, with other elements falling back into the shadows, and because the physical elements slip out of conscious awareness it becomes a disembodied experience. What is strange is what happens next - suddenly, as though a tipping point has been reached, I have an awareness that I can no longer 'feel' the paper between my fingers. It is as though my holding the paper has become a conscious idea before the sensation of me holding it returns to awareness. My experience of this is described best at first as an 'out of body experience' - are those my arms holding the paper? I become very afraid all of a sudden and shake the paper and slightly jump in my seat so as to remind myself that yes these are my limbs, yes I am embodied. I am relieved to observe that no-one else on the bus seems to have noticed my wobble, and the fear quickly passes.

\section{Reflection: towards explanations of dissociation and depersonalisation}


To gain a sense of what it felt like try sitting with your hands still on your lap, but then whilst your arms physically remain where they are imagine that they raise and open up as though to hold a newspaper. There is the impression that the arms are there but there's nothing of substance about them - they appear as phantom limbs. In his own autoethnographic account A Leg to Stand On, Sacks gives an account of his recovery after a serious climbing accident detached the quadriceps muscle in his left leg. Although the operation to repair the damage was a success, in the days following the operation Sacks experienced a complete disassociation from his leg - it no longer felt like his leg, completely paralysed, a dead weight, and wrote about it seeming to exist in another dimension, with its own kind of reality

'The more I gazed at that cylinder of chalk, the more alien and incomprehensible it appeared to me. I could no longer feel it was 'mine', as part of me.

(Sacks, 1984 p72)

In Sacks' account it is as though his mind's remembering of what his leg ought to be like, how it ought to feel, did not chime with how the leg presented itself, thus triggering for him terrifying anxieties about the nature of existence itself. Indeed when Sacks did eventually recover sensation and movement, and was able to walk again he had described his experience as a spiritual drama and a journey to the underworld and back (ibid). Whilst Sacks' experience was sustained and the more terrifying for that, the momentary experience of physical derealisation had a similar nature. But this begs the question as to why, if the sensation of the paper in between the fingers slipping out of consciousness is an entirely natural event, something that would happen to any of us, how then it became a frightening disassociation event. Returning to the experience of chronic pain in the light of this we take the view that the experiences display a phobia of numbness and paralysis. It is as though numb limbs, such as you might encounter had you been sleeping in an awkward position in the night, have 
become a symbol of death. In addition to flight or fight strategies the human being may alternatively deploy a 'conservation-withdrawal' mechanism, in which parasympathetic nervous system activity predominates over sympathetic activity and one is immobile, passive and unresponsive (Schoenberg, 2007). We may imagine scenarios in which neither flight nor fight is possible - where there is no escape - and so instead one freezes, plays dead, with a potential evolutionary return if the aggressor then loses interest and moves on. However as Levine (1997) observes, this immobilisation can potentially be traumatic - the impulse towards a surge in sympathetic activity through the fight or flight mechanism is not discharged. When we go into freeze mode it is as though we apply the brakes whilst we are still accelerating thus creating a 'forceful turbulence in the body resembling a tornado' (ibid p27). The internal recycling of affect can easily be imagined in the case of a person appearing outwardly composed and instead channeling all that excess of affect into jaw tension. Experiences of disassociation seem to appear in times of heightened anxiety and stress. It is like an overflow mechanism, like the overflow in a sink. We can cope with and digest the stresses and anxieties of every day up to a threshold level, but beyond this point psychosomatic symptoms are activated - it is as though they have become receptacles for excesses of affect.

\section{Having a body vis-à-vis being a body}

Where we experience our selves dualistically the body performs physical functions, such as digesting food, circulating blood and oxygen, and providing locomotion when the mind wills it so, but the mind is the source of ideas, of decision making and memory; the mind is still synonymous with the spirit that depends on the body but is not the same as the body. As such we experience ourselves as having a body. In contrast embodied consciousness notices how 
the stomach churns in anxiety and fear, how the cheeks flush with blood when we feel embarrassed, how eyes can fill with tears of sadness or joy, and how glaring teeth or tense muscles may indicate a sense that one is under attack. We then experience ourselves as being a body.

It is easer to appreciate the experience of being a body when somatic symptoms quieten. We can then identify with layers of bone and muscle, bile and blood and circulatory organs and tissues, the brain and the central nervous system and the nervous fibers branching out to all extremities, and the bulbs of sensory organs through which we relate with other bodies. However this is easily overwhelmed by the more common concept that we have a body, and indeed that it has to be disciplined (Frank, 2010). Periods of tiredness, or of being on a low ebb, or of a lot of feelings to digest and work through, are unwelcome distractions when we have much work to do. Rather than heeding these calls for a change in rhythm or position, we opt to push on through; the agenda setting part of the mind overrides these apparently unwanted and unproductive physical aspects. It often tends to be in precisely those moments when we opt to push on through that the pain surges, a pattern observed by other sufferers of chronic pain (see Doran, 2014).

We take the view that the journey that has been described in this article, charts a tentative personal migration from a state of having a body - from the mind/body dualism implicit in that idea - towards an internalised sensibility of being a body, i.e. that we are our body. Practically this means responding to the ebbs and flows of being a body, resisting the urge to 'push on through', and embracing the spectrum of emotions that colour our perceptions rather than attempting to rise above to a more 'objective' position. Contemporary literature advocates a more collaborative approach to the treatment of psychosomatic conditions, with a deeper quality of communication between the patient and practitioners, and indeed between the practitioners themselves (as in Edwards et al 2010, Druss \& Walker 2011, and Burton 
2014). The division of labour in conventional medicine can have the effect of excluding the emotional colouring of experience from the sphere of legitimate medical data, and likewise that psychotherapy, in the pursuit of free association and metaphor, loses its moorings in biology and ecology; from where psyche owes her origins. The FA has found that as he is able to re-embody thought and emotion, that depersonalisation attacks are less frightening, and indeed less common. The acceptance and recognition of vulnerabilities - such as, in the case of this investigation, a phobia of numbness and paralysis - also had the effect that in real-time experiences of depersonalisation the symptoms could be 'turned down' or would dissipate altogether. In this case progress with the jaw pain was less tangible and understanding the triggers and patterns of the pain is much clearer. Nevertheless the symptoms have demanded reflection upon them and this has facilitated a heightened level of self-awareness and an ability to see oneself as a body, rather than as merely having a body.

The essential issue here for therapists is whether therapeutic practice supports clients' experience of being in a body or not. Our hypothesis is that it does not because of excessive psychologising as a result of the emphasis on the relationship and the underlying antagonisms towards medical thinking and by implication somatic phenomena. When therapists do focus on somatic experiences they tend to do so in a relational and psychologising way. An example of this would be the concept of somatic countertransferenece which is viewed as informing the therapist of the inner psychological state of the client (Orbach, 2009). In other words the body is psychologised. Only when the body is addressed as body is the reality of being a body fully addressed; otherwise it remains an appendage of the psyche and therapists are no different from those doctors referred to in the section on alienation. They also fail to recognize the dissociative mechanisms described in this section. Embodied therapy requires an explicit focus on the body. 


\section{Implications for Practice}

Those therapists who have experienced being both patient and practitioner, and have researched into this, find that their practice is influenced and shaped by the research. For instance, as a practicing psychological therapist presently working with people who suffer with medically unexplained symptoms, the FA follows his own principle of regarding symptoms as serving as an overflow for excesses of affect and has found it important to treat symptoms as symptoms. Very typically in the therapy literature psychosomatic symptoms are treated as serving a symbolic function, and as such have to be decoded. However this approach does not tend to be helpful to the sufferer and may reaffirm the idea that the symptoms are 'all in your head' even though they know that the symptoms are very real. Furthermore, therapeutic focus on the symptoms in and of themselves may collude with the person's increasing preoccupation with them - a tendency that is known to lead to less healthy behavioural patterns, which in turn exacerbate the symptoms further (as in Webster et al, 2015). Treating symptoms as symptoms communicates to the sufferer that medically unexplained symptoms can, and often do, naturally recede as wider quality of life, self-esteem, and capacity for emotional experience improves. Recognising the materiality of symptoms, it is for the GP and other health professionals to work on the symptoms e.g. through pain relief or physical therapies. Instead we stress the importance of assisting the person to develop an embodied awareness - becoming more aware of the psychosocial triggers, patterns and contexts that underpin the flare-ups of symptoms. This awareness can be encouraged through the deployment of autoethnographic methods such as diarying where the patient is willing and able to do this. The process of contextualization of symptoms enables the sufferer to develop their own narrative account of their condition within their life story as retold in the therapeutic situation. As the evidence indicates, people who are able to develop their own narrative explanation for their symptoms have a better prognosis than those who are mystified by them (Deary et al, 2006). The person may thus be assisted in 
identifying more helpful health beliefs and patterns of behaviour that enable them to live well despite their condition. Recognising the social dynamics of medically unexplained symptoms, and particularly the stigma often associated with these, it is also important for the person to be assisted in managing the impact of the condition on their relationships - for example with partners, carers, family, and work colleagues - and indeed over their own identity: how their own sense of being in the world has been challenged by their condition. Finally, as trauma often serves as a seminal event in the appearance of medically unexplained symptoms and especially in functional syndromes such as fibromyalgia, therapists should not only attend to the question of when symptoms first appeared but also the appropriateness of doing trauma work with the person. Here Levine (1997) and Rothschild (2000) provide essential guidance for the practitioner. It is our belief that a person does not need a concrete diagnosis or medical explanation for their physical symptoms in order for them to begin to make substantial progress in sense making and improving their quality of life. Indeed talking therapy with its emphasis on context and meaning is well placed to accommodate the psychosocial dynamics of uncertainty.

\section{Conclusion}

We have endeavoured in this article to demonstrate through thick descriptive accounts of somatic symptoms, the wider contexts in which these symptoms are expressed. A GP ascribed the term 'depersonalisation attacks' to the FA's strange out of body experiences years ago but it was only recently upon reflection in depth that the connection with a phobia of numbness and paralysis and its basis in traumatic experience became apparent. This then provided significant relief from those symptoms. 
Thick description accounts demonstrate that if we are to make sense of medical conditions that for whatever reason have become 'stuck', particularly where there are discernible psychosomatic qualities, we may consider a great many layers of personhood, and symptoms and pathologies reverberate throughout these. An ongoing process of recontextualisation may yield tangible insights about the aetiology, management of and recovery from those symptoms. Thus ethnography, as a result of broadening the scope and viewing old problems through fresh eyes, must be considered a crucial research strand.

In view of these considerations there is a strong case for further research into the multi-layered contexts of medically unexplained symptoms - patient narratives of their experiences may be enlightening, but so may the experiences of counsellors and psychotherapists whom will assist the person in uncovering these contexts. Research that aimed to understand the processes through which recontextualisation was facilitated, what recontextualisation looked like, and the tangible consequences this had for the management, incidence, and experiencing of symptoms may lead to important innovations in the care offered by counsellors and psychotherapists and thereby give psychological therapists a greater sense of confidence and direction when encountering these often mysterious physical symptoms.

\section{References}


Alliance for Counselling and Psychotherapy (2009). Quote from Aldridge, S. 2009. Making Your Mind Up, in Therapy Today, vol 20, issue 4, May 2009. http://www.therapytoday.net/article/show/365/making-your-mind-up/ ; Retrieved on 5 March 2016

Andersen, R.S. \& Risør, M. B. (2014). The Importance of Contextualisation: Anthropological reflections on descriptive analysis, its limitations and implicaitions. Anthropology and Medicine, 2014

Barry, C.A. (2006). The role of evidence in alternative medicine: Contrasting biomedical and anthropological approaches. Social Science \& Medicine 62 (2006) 2646-2657

Bermingham, S.L.; Cohen, A.; Hague, J.; Parsonage, M. 2010. The cost of somatisation amongst the working-age population for the year 2008-2009. Mental Health in Family Medicine. 2010 June; 7(2): 71-84

Blackmore, S. (1996). Conversations on Consciousness. New edition : Oxford OUP

Burton, C. (2014). Can we explain medically unexplained symptoms? (editorial) Family Practice, 2014, Vol. 31, No. 6, pp623-624

Clifton, S. (2014). Grieving for my broken body: An autoethnographic account of spinal cord injury as an experience of grief. Disability and Rehabilitation 36(21): 1823-1829

Deary et al. (2007). The Cognitive Behavioural Model of Medically Unexplained Symptoms: a theoretical and empirical review. Clinical Psychology Review 27 (2007) 781-797

Doran, N.J., (2014). Experiencing wellness within illness : Exploring a mindfulness-based approach to chronic back pain. Qualitative Health Research, 24 (6), pp. 749-760. 
Druss, B.G. \& Walker, E.R. (2011). Mental Disorders and Medical Comorbidity. The Synthesis Project, Report number 21

Edwards et al (2010). The treatment of patients with medically unexplained symptoms in primary care: a review of the literature. Mental Health in Family Medicine 2010;7:209-21

Elwood, T.W. (2012). Viewing Health Care through a Semiotic Veil of Signs. Journal of Allied Health, Spring 2012, Vol 41, No 1

Ettorre, E. (2005). Gender, Older Female Bodies and Autoethnography: finding my feminist voice by telling my illness story. Women's Studies International Forum 28 (2005) 535-546

Ettorre, E. (2010). Nuns, Dykes, Drugs, and Gendered Bodies: An Autoethnography of a Lesbian Feminist's Journey Through 'Good Time' Sociology. Sexualities. 13(3), pp.295-315

Fisher, P. and Lees, J. (2015). Narrative approaches in mental health: preserving the emancipatory tradition, Health: An Interdisciplinary Journal for the Social Study of Health, Illness and Medicine, 1-17

Fonagy, P., \& Bateman, A. (2006). Progress in the treatment of borderline personality disorder. British Journal of Psychiatry, 188, 1-3.

Francis, R. (chair) (2013). Report of the Mid-Staffordshire NHS Foundation Trust Public Inquiry : Executive Summary. London : The Stationary Office

Frank, A.W. (2010). The Wounded Storyteller: Body, Illness and Ethics. USA : University of Chicago Press

Freud, S. (1954). The Origins of Psychoanalysis: Letters to Wilhelm Fliess, Drafts and Notes 1887-1902. New York : Basic Books 
Gask, L., Dowrick, C., Salmon, P., Peters, S., \& Morriss, R. (2011). Reattribution reconsidered: Narrative review and reflections on an educational intervention for medically unexplained symptoms in primary care settings. Journal of Psychosomatic Research 71 (2011) 325-334

Geertz, C. (1973). The Interpretation of Cultures: selection of essays. New York : Basic Books Gerrish, K \& Lacey, A. (eds) 2010. The Research Process in Nursing, $6^{\text {th }}$ edition. UK : WileyBlackwell

Hinton, D. \& Kirk, S. 2016. Families' and healthcare professionals' perceptions of healthcare services for children and young people with medically unexplained symptoms: a narrative review of the literature. Health and Social Care in the Community (2016) 24(1), 12-26 Kierans, C. (2005). Narrating Kidney Disease: the significance of sensation and time in the emplotment of patient experience. Culture, Medicine and Psychiatry 29: 341-359, 2005.

King, K.P. (2014). A Journey with Chronic Pain: Self-directed learning as survival. New Horizons in Adult Education \& Human Resource Development 26(2), 5-18

Lees, J. (2011). Counselling and psychotherapy in dialogue with complementary and alternative medicine. British Journal of Guidance and Counselling, 39(2), 117-130. Lees, J. (2013). Psychotherapy, complementary and alternative medicine and social dysfunction. European Journal of Psychotherapy and Counselling, 15(3), 201-203.

Lees, J. (2016) [ed]. The future of psychological therapy: from managed care to transformational practice. London: Routledge.

Leone, S.S.; Wessely, S.; Huibers, M.J.H.; Knottnerus, J.A.; \& Kant, I. (2011). Two sides of the same coin? On the history and phenomenology of chronic fatigue and burnout.

Psychology and Health Vol. 26, No. 4, April 2011, 449-464 
Levine, P.A. (1997). Waking the Tiger: Healing Trauma. USA : North Atlantic Books

McEwan, B. (2000). Allostasis and allostatic load: implications for neuropsychopharmacology, Neuropsychopharmacology, 22 (2): 108-124.

Meany, B. (2001). Maternal care, gene expression, and the transmission of individual differences in stress reactivity across generations. Annual Review of Neuroscience, 24, 11611192

Mobini, S. (2015). Psychology of Medically Unexplained Symptoms: A Practical Review. In Cogent Psychology (2015), 2: 1033876

Moltmann-Wendel, E. (1995). I Am My Body: A theology of embodiment. New York : Continuum

Neville-Jan, A. (2003). Encounters in a World of Pain. American Journal of Occupational Therapy. 57(1), pp.88-98

Orbach, S. (2009). Bodies. London : Picador.

Porcelli, P., De Carne, M., \& Leandro, G. (2014). Alexithymia and gastrointestinal-specific anxiety in moderate to severe irritable bowel syndrome. Comprehensive Psychiatry. Jun 2014 Puente, C.P., Furlong, L.V., Gallardo, C.E., Mendez, M.C., \& McKenney, K. (2013). Anxiety, depression and alexithymia in fibromyalgia: Are there any differences according to age? Journal of Women \& Aging. Vol.25(4), Oct 2013, pp. 305-320.

Quillman, T. (2013). Treating trauma through three interconnected lenses: Body, personality, and intersubjective field. Clinical Social Work Journal, 41(4), 356-365 
Ramo-Fernandez, L., Schneider, A., Wilker, S., \& Kolassa, I.-T. (2015). Epigenetic alterations associated with war trauma and childhood maltreatment. Behavioral Sciences \& the Law, 33(5), 701-721

RCGP (Royal College of General Practitioners). (2014). Guidance for Health Professionals on Medically Unexplained Symptoms (MUS), [online]. [Accessed 16 ${ }^{\text {th }}$ February 2015].

Available from: $\quad$ http://www.rcgp.org.uk/clinical-and-research/clinical-
\begin{tabular}{|l|}
\hline resources/ /media/Files/CIRC/Mental\%20Health\%20- \\
\hline \%202014/4\%20Medically\%20Unexplained\%20Symptoms\%20\%20guidance\%202014.ashx \\
\hline
\end{tabular}

Ricciardi, L \& Edwards, M.J. (2014). Treatment of Functional (Psychogenic) Movement

Disorders. Neurotherapeutics (2014) 11:201-207

Roth, W-M. (2012). First Person Methods: Towards an Empirical Phenomenology of Experience. Netherlands : Sense Publishers

Rothschild, B. (2000). The Body Remembers: the psychophysiology of trauma and trauma treatment. USA : W.W. Norton \& Company

Sacks, O. (1984). A Leg to Stand On. New York : Harper and Row

Save-Pedebos, J, Bobet, R, \& Morel, P. (2013). Psycho-affective characteristics in adults with atopic dermatitis. Pratiques Psychologiques. Vol.19(1), Mar 2013, pp. 29-39.

Schoenberg, P. (2007). Psychosomatics: The Uses of Psychotherapy. UK : Palgrave Macmillan

Steiner, R. (1920). Spiritual Science and Medicine. London: Rudolf Steiner Press, 1975 
Suzuki, LA. Auhluwalia, MK. Mattis, JS. \& Quizon, C.A. (2005). Ethnography in Counseling Psychology Research: Possibilities in Application. Journal of Counseling Psychology 2005. Vol 52, number 2, 206-214

Thorlby, R., Smith, J., Williams, S., \& Dayan, M. (2014). The Francis Report: One Year On. Nuffield Trust

Webster, R., Thompson, A.R., \& Norman, P. (2015). 'Everything's fine, so why does it happen?' A qualitative investigation of patients' perceptions of noncardiac chest pain. Journal of Clinical Nursing, 24, 1936-1945

Wilbers, L.E. (2015). She has a pain problem, not a pill problem: Chronic pain management, stigma and the family - an autoethnography. Humanity \& Society, Vol. 39(1) 86-111 Yalom, I.D. (1980). Existential Psychotherapy. United States of America : Yalom Family Trust Yee, J. (2014). Finding the Words: How the intersection of Asian American Studies and Women's Studies helps me to survive kidney cancer. Frontiers 2014 Vol. 35, No. 3 